\title{
About a Method of Calculation of Importance Degree of Geometrical Characteristics to Identify a Human Face on the Basis of Photo Portraits
}

\author{
Tofiq Kazimov, Shafagat Mahmudova*
}

Institute of Information Technology of ANAS, Baku, Az1141, Azerbaijan

\begin{abstract}
The paper offers a new algorithm to find coefficients which determines importance degree of the values of geometrical characteristics used to identify a human face on the basis of photo portraits. Significance of coefficients determining importance degree of the values of geometrical characteristics for identification is explained. Determination of coefficients determining importance degree of the values of geometrical characteristics for identification leads to the reduction in the number of values of insignificant geometrical characteristics, as well as to the improvement of identification quality and to the decrease in time spent for identification.
\end{abstract}

Keywords Recognition, Identification, Geometrical Characteristics, Importance Degree, Coefficient

\section{Introduction}

Modern information and communication technologies (ICT) enable the development of various areas of great importance, as well as of biometric technology. The expansion of the fields of application of these technologies plays an important role in preventing a number of dangerous incidents. It is obvious that the prevention of dangerous manifestations, such as the prevention of international terrorism, transnationals organized crime, as well as illegal weapon and drug transportation is one of the main duties of each state. One of the methods in detecting and neutralizing hazardous manifestations is just the advantages of biometric identification technologies. Biometric technologies particularly strengthen reliable control passport-visa control and other identification documents.

Information on the dynamics of biometric technology market given by the world-famous International Biometric Group, gives a way to say: Taking into account the unique characteristics of a person chosen separately, biometric technology was organized on the basis of biometrics[1, 8, 9].

People differ significantly from each other for the sizes and the arrangement of such face elements as eyes, eyebrows, noses, ears, mouths, etc. Therefore, the first approach to the problem solution of automatic person face identification by photo portrait was based on the selection and comparison of

* Corresponding author:

shafagat557@mail.ru (Shafagat Mahmudova)

Published online at http://journal.sapub.org/computer

Copyright (C) 2012 Scientific \& Academic Publishing. All Rights Reserved some anthropometric face peculiarities. This method has been used in experimental criminalities for years. This technique was especially effective when a person did not have a photograph except the one in a passport[2].

Paper[3] is devoted to the recognition of a human face on the basis of a photo portrait. For face recognition based on a photo portrait, the authors developed 19 anthropometric face points. These points are chosen from the point of resistance to slight changes (caused by the angle, light, facial expression, cosmetics, age, and so on). An algorithm has been developed for calculating the values of the distances between these points and of geometrical characteristics of the human face. It is shown that the difference of the developed algorithm from the other existing ones is that compared with the other photos stored in the database it works even in the absence of any other information about the person except the image described in the photo[10,11].

The development principles of "Recognition" biometric identification system (RBIS) are explained on the basis of algorithm given to identify a human on the basis of photo portraits in paper[4], and a database with a developed structure is organized for it. Various sized images of $n$ persons and individual data for each (first name, middle name, last name, date of birth, eye colour, height and etc.) were included in the database. The paper also describes an algorithm for default addition of the values of the geometrical characteristics, for search and identification of an image of a human face on the basis of photo portrait in the database[12, 13].

The paper[5] provides information about the algorithms developed for normal distribution of the values of geometrical characteristics used in the recognition of a 
human face on the basis of photo portrait and to define trust interval of the geometrical characteristics. It is shown that the determination of normal distribution of geometrical characteristics is of great importance for various reasons. $m$ selection value is randomly taken from the values of geometrical characteristics and its normal distribution is investigated $[6,14,13,15]$.

The paper[5] provides information about the algorithms developed to define trust interval of the values of geometrical characteristics in the recognition of a human face on the basis of photo portrait. On the basis of the conducted researches, the real interval values of distances between the anthropometric points of a human face are established. With the help of fuzzy calculation, interval values of geometric characteristics values, proper to the same points, are found $[6,7,15]$.

Finding coefficients which determine importance degree of the values of geometrical characteristics used to identify a human face on the basis of photo portraits is of great importance for the recognition process from the various views. Determination of coefficients determining importance degree of the values of geometrical characteristics for identification leads to the reduction of the number of values of insignificant geometrical characteristics, as well as to the improvement of identification quality and to the decrease of time spent for the identification.

\section{Problem Statement}

A new algorithm is proposed in this paper to find the coefficient which determines importance degree of the values of geometrical characteristics. Let us explain the essence of the algorithm. The values of geometrical characteristics of $n$ quantity used for the identification are divided into the clusters of $m$ quantity for the same sign. To determine the importance degree of the values of geometrical characteristics an identification process is carried out temporarily replacing each value of geometric characteristics of each person with the other values taken from the replacement interval, and the impact of the replacement in the recognition process is assessed.

\section{Importance Degree Algorithm}

Let us mark the wanted photo portrait possessing geometric characteristics of $m$ quantity, i.e., $m$ sized point with $F^{*}\left(p_{1}^{*}, p_{2}^{*}, \ldots, p_{m}^{*}\right)$, photo portraits in the database with $F_{i}\left(p_{i 1}, p_{i 2}, \ldots, p_{i m}\right),(i=\overline{1, n})$. If we mark $F_{i}$ points and distances of $F^{*}$ point with $S_{i}$, then

$$
S_{i}\left(F^{*}, F_{i}\right)=\sum_{k=1}^{m}\left(p_{k}^{*}-p_{i k}\right)^{2}, i=\overline{1, n},
$$

Where $n$ indicates the number of photo portraits in the data base. Let us divide geometrical characteristics of the photo portraits in the data base into
$K_{j}\left(p_{i j}, i=\overline{1, n}\right),(j=\overline{1, m})$ clusters of $m$ quantity. If we mark replacement intervals of the parameters of each $K_{j},(j=\overline{1, m})$ cluster with $\left[\alpha_{j}, \beta_{j}\right],(j=\overline{1, m})$, then inequality

$$
\alpha_{j} \leq p_{i j} \leq \beta_{j}, \quad i=\overline{1, n}, j=\overline{1, m},
$$

can be right for any $p_{i j}$.

To determine importance degree of geometrical characteristics of each photo portraits, i.e. of $p_{i j}$ parameters for the identification, let us divide $\left[\alpha_{j}, \beta_{j}\right]$ interval of each $K_{j}(j=1, m)$ cluster into the equal $t \geq 10$ parts by $h_{j}$ step.

$$
\begin{aligned}
& h_{j}=\left(\beta_{j}-\alpha_{j}\right) / t, j=\overline{1, m}, \\
& x_{j k}=\alpha_{j}+k h_{j},
\end{aligned}
$$

$t$ - is an integer number.

Replacing $x_{j k} \in\left[\alpha_{j}, \beta_{j}\right],(k=\overline{0, t} ; j=\overline{1, m})$ points consistently instead of the values of $l$ the $(l=\overline{1, m})$ coordinates of $F^{*}$ points, we achieve the point of $(t+1) m$ quantity. Let us mark them with $F T_{k l}(k=\overline{0, t} ; l=\overline{1, m})$.

Let us calculate $\omega_{j}$ coefficient indicating $S T_{k i}\left(F_{i}, F T_{k i}\right)$ distances between these points and $F_{i},(i=\overline{1, n})$ points in the database and determining the efficiency degree of geometrical characteristics.

$$
\omega_{j}=\left(\frac{1}{n(t+1)} \sum_{i=1}^{n} \sum_{k=0}^{t} \frac{S T_{k i}-S_{i}}{x_{j k}-p_{i j}}\right)^{-1}, j=\overline{1, m},
$$

Note that, calculating the distance between the other photo portraits existing in the database and the two points in 16-dimensional space, the photo portrait of any person is compared with the following formula in the work[5].

$$
S_{i}\left(F^{*}, F_{i}\right)=\sqrt{\sum_{k=1}^{m}\left(p_{k}^{*}-p_{i k}\right)^{2}}, i=\overline{1, n},
$$

In this paper, the formula (5) is replaced with the formula (1). The aim of the replacement is to accelerate the identification process and to reduce the time spent for the identification. Including the coefficient which determines importance degree of the values of geometrical characteristics, into the formula (1), we can increase the importance of the recognition and may not take into account insignificant geometrical characteristics. When in a database it is too many records, then this replacement very important.

Including the coefficient (4) into the formula (1), the following distance formula is achieved:

$$
S_{i}\left(F^{*}, F_{i}\right)=\sum_{k=1}^{m} \omega_{j}\left(p_{k}^{*}-p_{i k}\right)^{2}, i=\overline{1, n} ; j=\overline{1, m},
$$




\section{Experimental Test}

As it is mentioned above, a large number of experiments have been carried out at TBIS on the basis of above mentioned algorithm in order to calculate the coefficients which determine importance degree of the values of geometrical characteristics used to identify a human face on the basis of photo portraits.

In particular cases, using the values $n=102, m=18$, $t=10$ the values proper to the values of the geometrical characteristics of 10 persons in accordance with the 1 st value of the cluster have been calculated through the formulas (1), (3), (4) and (6). Some of the results of the conducted experiments are shown in table 1, figure 1, figure.2, figure.3, figure. 4 in the form of graphics.

Table1 1. Values found on the basis of given algorithms

\begin{tabular}{|c|c|c|c|}
\hline \multicolumn{4}{|c|}{ P11 } \\
\hline 2,21 & 0,09 & 0,09 & 0 \\
\hline 2,22 & 0,08 & 0,08 & 0,010 \\
\hline 2,24 & 0,06 & 0,06 & 0,030 \\
\hline 2,25 & 0,05 & 0,05 & 0,040 \\
\hline 2,27 & 0,03 & 0,03 & 0,060 \\
\hline 2,28 & 0,02 & 0,02 & 0,070 \\
\hline 2,29 & 0,01 & 0,01 & 0,080 \\
\hline 2,31 & 0,01 & 0,01 & 0,080 \\
\hline 2,32 & 0,02 & 0,02 & 0,070 \\
\hline 2,34 & 0,04 & 0,04 & 0,050 \\
\hline 2,35 & 0,05 & 0,05 & 0,040 \\
\hline \multicolumn{4}{|c|}{ P12 } \\
\hline 2,21 & 0,11 & 0,06 & 0 \\
\hline 2,22 & 0,12 & 0,07 & 0,01 \\
\hline 2,24 & 0,14 & 0,09 & 0,03 \\
\hline 2,25 & 0,15 & 0,1 & 0,04 \\
\hline 2,27 & 0,17 & 0,12 & 0,06 \\
\hline 2,28 & 0,18 & 0,13 & 0,07 \\
\hline 2,29 & 0,19 & 0,14 & 0,08 \\
\hline 2,31 & 0,21 & 0,16 & 0,10 \\
\hline 2,32 & 0,22 & 0,17 & 0,11 \\
\hline 2,34 & 0,24 & 0,19 & 0,13 \\
\hline 2,35 & 0,25 & 0,2 & 0,14 \\
\hline \multicolumn{4}{|c|}{ P13 } \\
\hline 2,21 & 0,21 & 0,14 & 0 \\
\hline 2,22 & 0,22 & 0,15 & 0,01 \\
\hline 2,24 & 0,24 & 0,17 & 0,03 \\
\hline 2,25 & 0,25 & 0,18 & 0,04 \\
\hline 2,27 & 0,27 & 0,2 & 0,06 \\
\hline 2,28 & 0,28 & 0,21 & 0,07 \\
\hline 2,29 & 0,29 & 0,22 & 0,08 \\
\hline 2,31 & 0,31 & 0,24 & 0,1 \\
\hline 2,32 & 0,32 & 0,25 & 0,11 \\
\hline 2,34 & 0,34 & 0,27 & 0,13 \\
\hline 2,35 & 0,35 & 0,28 & 0,14 \\
\hline \multicolumn{4}{|c|}{ P14 } \\
\hline
\end{tabular}

\begin{tabular}{|c|c|c|c|}
\hline 2,21 & 0,01 & 0,21 & 0 \\
\hline 2,22 & 0,01 & 0 & 0,21 \\
\hline 2,24 & 0,03 & 0,02 & 0,19 \\
\hline 2,25 & 0,04 & 0,03 & 0,18 \\
\hline 2,27 & 0,06 & 0,05 & 0,16 \\
\hline 2,28 & 0,07 & 0,06 & 0,15 \\
\hline 2,29 & 0,08 & 0,07 & 0,14 \\
\hline 2,31 & 0,1 & 0,09 & 0,12 \\
\hline 2,32 & 0,11 & 0,1 & 0,11 \\
\hline 2,34 & 0,13 & 0,12 & 0,09 \\
\hline 2,35 & 0,14 & 0,13 & 0,08 \\
\hline \multicolumn{4}{|c|}{$\mathbf{P 1 5}$} \\
\hline 2,21 & 0 & 0,04 & 0 \\
\hline 2,22 & 0,01 & 0,005 & 0,04 \\
\hline 2,24 & 0,03 & 0,02 & 0,02 \\
\hline 2,25 & 0,04 & 0,03 & 0,01 \\
\hline 2,27 & 0,06 & 0,05 & 0,01 \\
\hline 2,28 & 0,07 & 0,06 & 0,02 \\
\hline 2,29 & 0,08 & 0,07 & 0,03 \\
\hline 2,31 & 0,1 & 0,09 & 0,05 \\
\hline 2,32 & 0,11 & 0,1 & 0,06 \\
\hline 2,34 & 0,13 & 0,12 & 0,08 \\
\hline 2,35 & 0,14 & 0,13 & 0,09 \\
\hline
\end{tabular}

Table1 2. Coefficients determining importance degree of geometrical characteristics (for the values of the 1st, 2nd, 3rd geometrical characteristics)

\begin{tabular}{|c|c|}
\hline & Coefficient values \\
\hline$\omega_{1}$ & 1,39 \\
\hline$\omega_{2}$ & 0,70 \\
\hline$\omega_{3}$ & 0,80 \\
\hline
\end{tabular}

The values proper to the given formulas have been calculated for other persons in this way, as well.

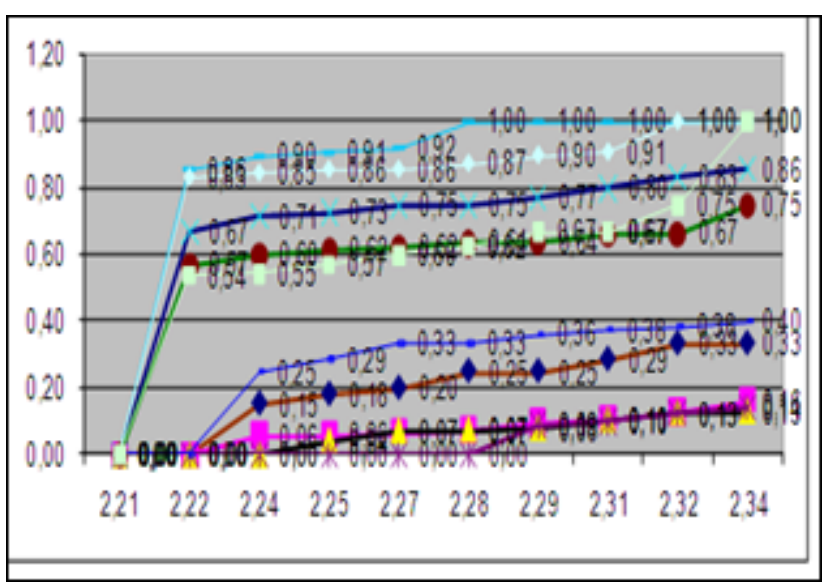

Figure 1. Comparison of the distance values found in accordance with the values of trust intervals proper to the values of the 1stgeometrical characteristics (10 persons)

$102 * 19 * 5$ (9690) experiments have been carried out on the basis of the data of 102 persons through TBIS. The values $\omega_{j}(j=\overline{1, m)}$ are shown in the table 2 . 
The authors have established biometric identification system in accordance with anthropometric points of a human face by the photo portrait on the basis of obtained scientific results.

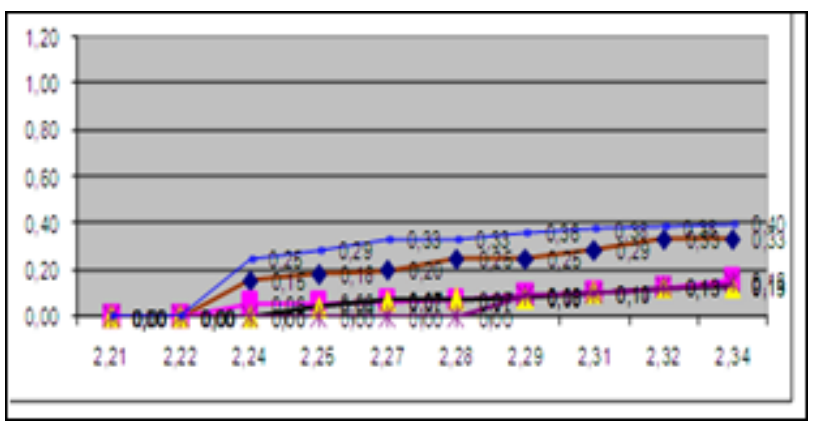

Figure 2. Comparison of the distance values found in accordance with the values of trust intervals proper to the values of the1st geometrical characteristics (females)

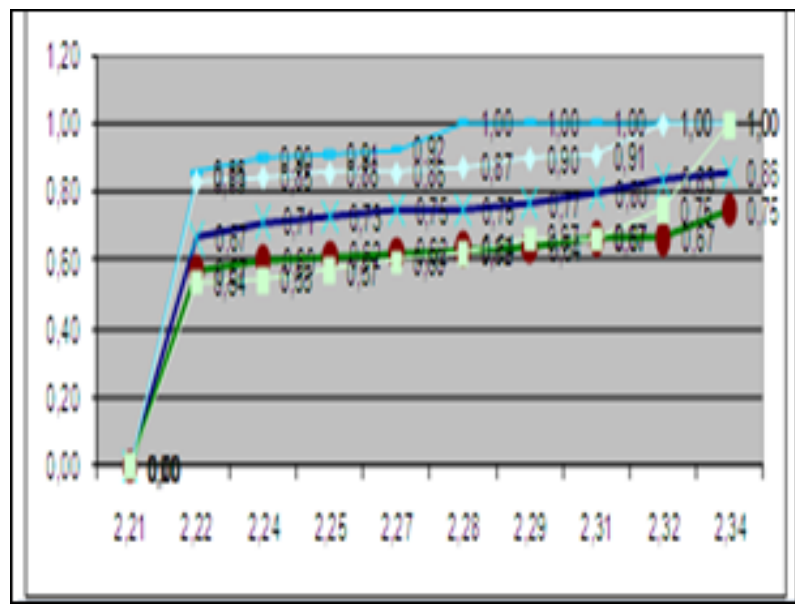

Figure 3. Comparison of the distance values found in accordance with the values of trust intervals proper to the values of the1st geometrical characteristics (males)

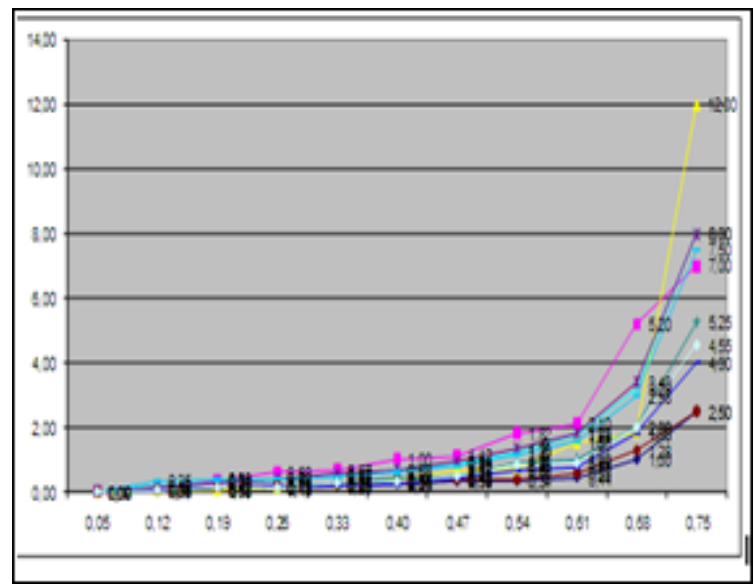

Figure 4. Comparison of the distance values found in accordance with the values of trust intervals proper to the values of the 2 nd geometrical characteristics (10 persons)

The software system is capable to detect the most similar faces comparing any photo portrait of any person uploaded to the system with other existing ones in the base. Note that the rumours regard to the identity of the hero of the mysterious "Mona Liza" by the prominent Italian artist Leonardo da Vinci is still not calming down. The disputes in connection with who is described in the portrait have been going on over more than 500 years.

The portraits of Leonardo da Vinci (figure 5) and Mona Liza (figure 6) painted in different years were included in the system database by the authors as an experiment. Two versions of identification process were carried out through the system. In the 1stversion the portrait of Mona Liza was included in the system base for identification and compared with the other ones existing in the database. Initially, the most similar portraits were Mona Liza (100\%) and the portrait of Leonardo da Vinci (99.5\%). In the2nd version the portrait by artist was included in the system for identification. In this case, the most similar portraits were the portrait of Leonardo da Vinci himself (100\%), and then the portrait of Mona Liza (99.5\%).

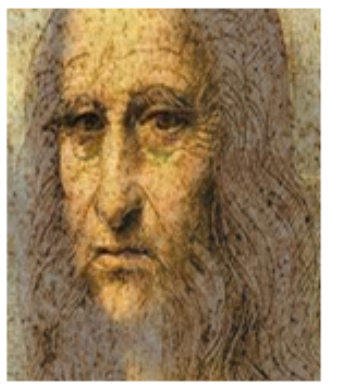

Figure 5. Leonardo Da Vinci
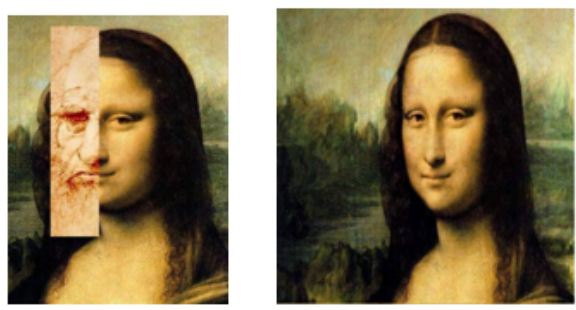

Figure 6. Mona Liza

\section{Conclusions}

A new algorithm has been proposed to find coefficients which determine importance degree of the values of geometrical characteristics used to identify a human face on the basis of photo portraits:

1. A formula is given to calculate distances between the wanted photo portraits possessing $m$ number of geometric characteristics with the points of photo portraits in the base;

2. A formula is given to calculate a step in appropriate intervals of each cluster in order to determine importance degree of the values of geometrical characteristics of each photo portrait for identification;

3. A formula is given to calculate $\omega_{j}(j=\overline{1, m})$ coefficients determining importance degree of the values of geometrical characteristics; 
4. Including $\omega_{j}(j=\overline{1, m})$ coefficients a distance formula is given for the identification.

The given algorithm leads to the reduction in the number of values of geometrical characteristics used for identification, as well as to the improvement of identification quality and to the decrease in time spent for the identification.

\section{REFERENCES}

[1] R.M.Boll, J.H.Connel, Sh.Pankanti, N.K.Ratkha E.U.Sen'or, "Rukovodstvo po biometrii", (Manual on Biometrics), Moscow: Tekhnosfera, 2007.

[2] D.I.Samal, V.V.Starovoitov, "Podkhody i metody raspoznav aniya lyudei po fotoportretam", (Approaches and Methods of People Recognition According to Photoportraits), Minsk, 1998.

[3] T.G. Kyazimov, Sh.J.Makhmudova, "Systems of People Computer Recognition According to Photopor traits", Informatsionnye tekhnologii, no. 1, pp. 13-16, 2009.

[4] T.G. Kyazimov, Sh.J.Makhmudova, "Automating System of People Recognition According to the Identifi cation Geometric Characteristics of Face Image", Telekommunikat sii, 2008, no. 11, p. 22-25.

[5] T.G. Kyazimov, Sh.J.Makhmudova, "The Effectiveness Increase of a System of Automatic Biometrical Identification Based on Photo Portraits", Automatic Control and Computer Sciences, vol. 45, no. 2, pp. 106-112, 2011.

[6] A.I.Orlov, "Matematika sluchaya: Veroyatnost' i statistika osnovnye fakty", Uchebnoe posobie, (Mathematics of Incident: Probability and Statistics - Fundamental Facts. Manual), Moscow, MZPress, 2004.
[7] S.V.Matsievskii, "Nechetkie Mnozhestva. Uchebnoe Posobie Fuzzy Ensembles. A Manual)”, Kaliningrad, KGU, 2004.

[8] I.Fomin, "Raspoznavanie obrazov. Teoriya I primeneniya", M.: Fazis, 2010, 368 pp.

[9] T.G. Kyazimov, Sh.J.Makhmudova, "About creation of system of computer recognition of people by photographs" / ICNNAI 2008, The Fifth International Conference on "Neural Networks and Artificial Intelligence", Minsk: May 27-30, 2008.

[10] T.G. Kyazimov, Sh.J.Makhmudova, Information identificati on system for identifying people by portrait photos, The Second International Conference "Problems of Cybernetics and Informatics", Baku, 2008, September 10.

[11] T.G. Kyazimov, Sh.J.Makhmudova Information identification system for identifying People by portrait photos, The sixth International scientific and technical conference "the Internet - Formation - the Science - 2008", Vinnitsa, 7 - 10 October, 2008.

[12] Sh.J.Makhmudova, "Definition of weight coefficient of geometric characteristics used for identification of human face on the basis of photo-portrait ICCIT2011, the 6th International Conference on Computer Sciences and Convergence Information Technology, 2011, November 29 to December 1 .

[13] T.G. Kyazimov, Sh.J.Makhmudova, "Recognition of the person with photographs", Information Technology:, Baku, 2010, $113 \mathrm{pp}$.

[14] R.Chellappa , P.Sinha , P.Jonathon, "Face Recognition by Computers and Humans", Computer, 2010, Date:February, pp. 46-55.

[15] T.G. Kyazimov, Sh.J.Makhmudova, "Methods of imroveme nt of efficiency in recognition identifications systems", The Third International Conference "Problems of Cybernetics and Informatics”, 2010, September 6-8, Baku, Azerbaijan. 